\title{
A Modified Partial Power structure for Quasi Z-Source Converter to Improve Voltage Gain and Power Rating
}

\author{
Shahin Honarmand ${ }^{1}$, Amirhossein Rajaei ${ }^{1, *}$, Mahdi Shahparasti ${ }^{2}{ }^{\circledR}$, Alvaro Luna ${ }^{2}$ and \\ Edris Pouresmaeil ${ }^{3, *}$ (D) \\ 1 Department of Electrical and Electronics Engineering, Shiraz University of Technology, Shiraz 71557-13876, \\ Iran; s.honarmand@sutech.ac.ir \\ 2 Department of Electrical Engineering, Technical University of Catalonia, 08222 Barcelona, Spain; \\ mahdi.shahparasti@upc.edu (M.S.); luna@ee.upc.edu (A.L.) \\ 3 Department of Electrical Engineering and Automation, Aalto University, 02150 Oslo, Finland \\ * Correspondence: a.rajaei@sutech.ac.ir (A.R.); edris.poursmaeil@aalto.fi (E.P.); Tel.: +98-917-300-0944 (A.R.)
}

Received: 18 April 2019; Accepted: 31 May 2019; Published: 4 June 2019

Abstract: Employing partial power processing (PPP) technique for quasi Z-source converter (QZSC) a new structure of the converter is presented. Using PPP technique although eliminates electrical insolation, but permits reducing voltage and current stress at the semiconductors, if compared with full power proposals. In this work, two PPP structures are discussed: A first one, similar to the basic topology, where the output voltage of the power converter is in series with the input voltage; and a second one, where the output is in series with the capacitor of the QZSC. This minor modification, which requires no extra elements, improves the power rating, voltage gain, and requires a lower transformation ratio. An experimental prototype of the proposed converter has been tested and the results are compared with other implementations, permitting to validate the theoretical analysis as well as the advantages that this proposal provides.

Keywords: partial power processing; quasi Z-source converters; high step up converters

\section{Introduction}

As one of the main backbones of the power electronics industry an uncountable number of research works have been devoted to the study and design of high efficiency, low power rating, and low cost DC/DC converters for different applications such as: PV, electrical equipment, electrical vehicles, energy storage, and communication systems. Furthermore, many researches have been made to improve the performance of conventional converters. One recent technique that is giving rise to good results is based on partial power processing (PPP) [1,2]. The basic principle of this technique is based on providing part of the input power directly to the output, meanwhile the rest is processed by the converter [1-13]. The main advantage of this technique is to level down the power rating of the elements as less power is handled by the converter. This is achieved without requiring to add or remove any element.

The main feature of the PPP technique is found in the connection between the source and the load [1]. The layout available in Figure 1 shows the two main topologies. The first type (Figure 1a), which is appropriate for boosting, has an output voltage equals to the sum of the source voltage and the output voltage of the converter [1,3-7]. The second one, shown in Figure 1b, is appropriate for buck application, and builds the output voltage taking the difference between system and converter input voltages [8,9].

Isolation is a big challenge in PPP applications $[1,2,10]$. However non-isolated converters can be considered in some cases [3-5]. For instance, in [11] a simple and commercially available non-isolated 
partial power (PP) boost converter for PV systems was integrated. Based on [12], the performance of this converter does not follow the PP method and acts like a full power converter (FPC). As described in $[1,3,4]$, if the average current passing through the direct power path is zero, the system's performance is similar to a full power processing converter. A dual input non-isolated partial power converter (PPC) was introduced in [13-15], which employs two similar PPC.

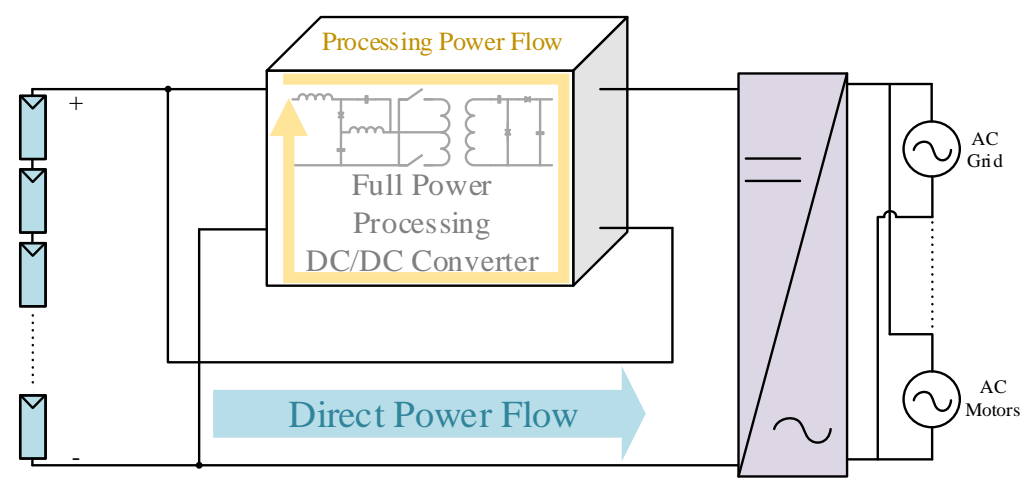

(a)

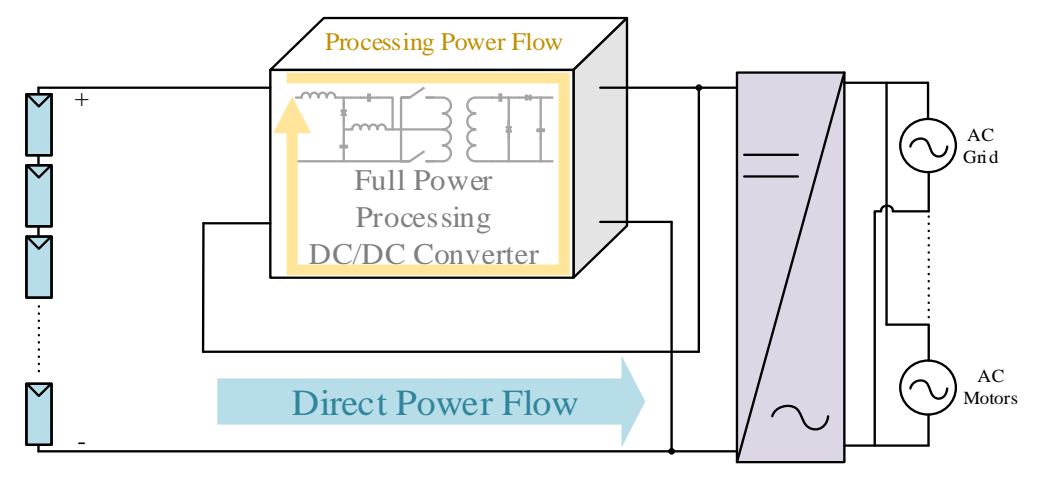

(b)

Figure 1. Basic structure of partial power processing (PPP system): (a) Input parallel output series, (b) Input series output parallel.

On the other hand, impedance network converters are widely investigated for low voltage renewable energy source applications. The main advantage of these converters lays on the fact that they can provide a high voltage step up; and the other merit is short circuit immunity [16-25]. The PPP technique can be applied to these types of converters in order to improve their performance. Z-source converter (ZSC) which is the first proposed structure of impedance network converters, includes an inductor and a capacitor that handle the charge and discharge cycles to provide the maximum power conversion ability during the shoot through time interval [19]. However, quasi ZSC (QZSC) which has been chosen in this paper, provides some advantages compared to ZSC, including continuous input current and wider boosting range [20,25].

After defining the topology different types of switching methods can be implemented such as: Using only one switch to shoot through switching, using two or three leg H-Bridge switching topology, and push-pull switching topology [21] (Figure 2). In this case reducing the number of switches and implementing a simple control using push-pull switching, have been prioritized in the selection of the proposed converter [22]. 


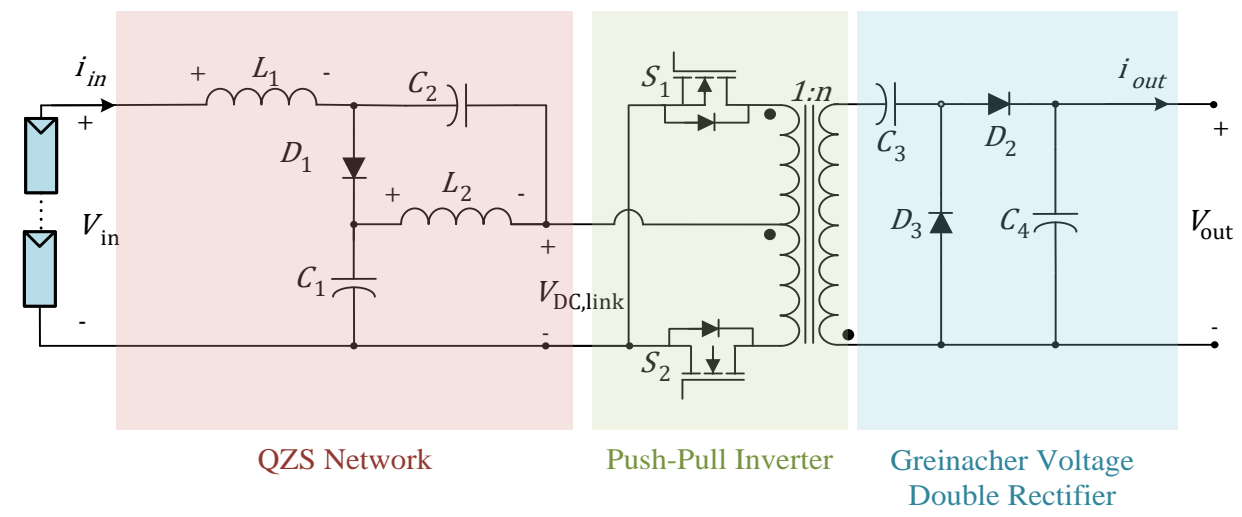

(a)

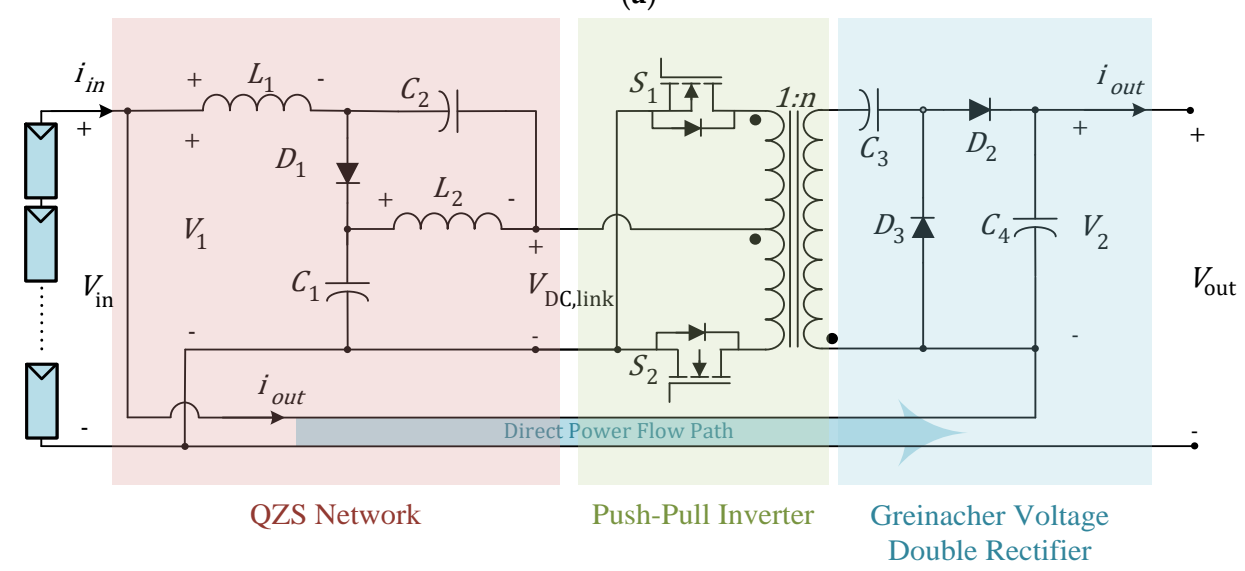

(b)

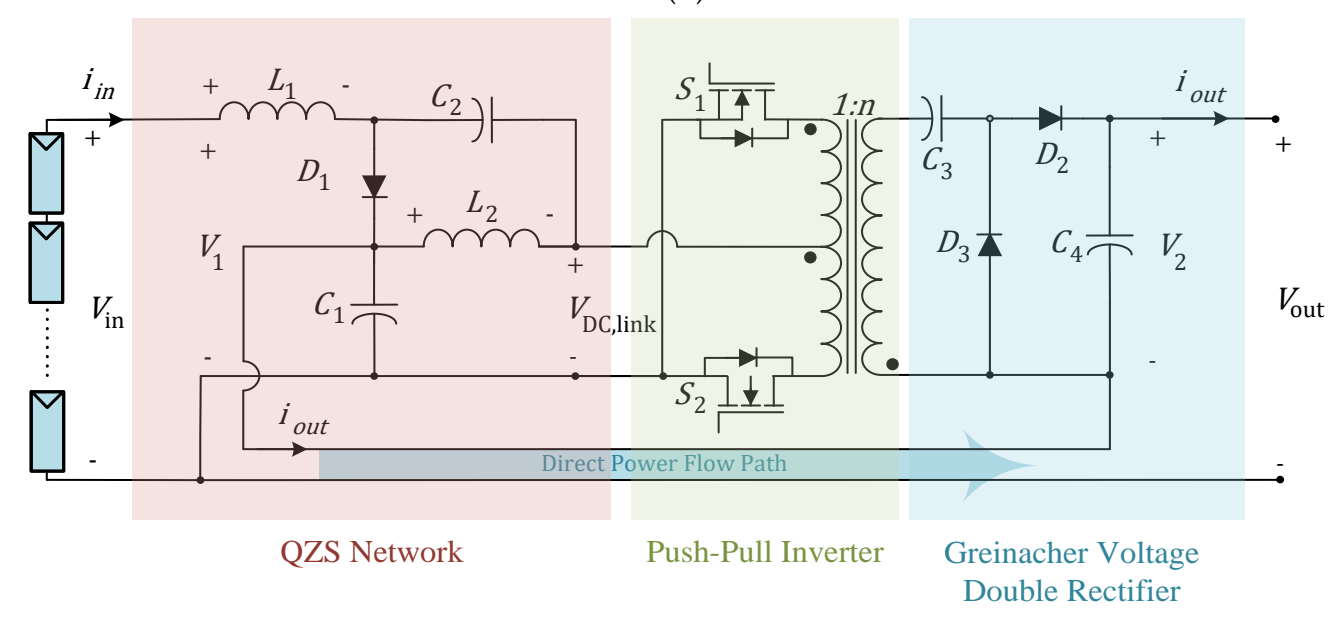

(c)

Figure 2. Equivalent circuits of the converters: (a) Full power quasi Z-source converter (QZSC), (b) Basic PPP QZSC, (c) Proposed PPP QZSC.

In this paper the isolated QZSC has been used with push pull switching method in the middle, as shown in Figure 2a. Two structures of PPC for this converter are presented: PP-QZSC (Figure 2b) and modified PP-QZSC (Figure 2c). The first type is based on the basic structure of PPP technique (as depicted in Figure 1a), while the structure is revised in the second one and this provides reduced voltage stress and higher voltage gain.

One of the main contributions of this paper is the use of the PPP technique for improving the voltage gain of the full power QZSC (FP-QZSC). The proposed method permits achieving a voltage gain 20\% higher than basic PPP system. 
In order to evaluate the performance of the modified PP-QZSC, its performance will be compared to traditional FP-QZSC and basic PP-QZSC in terms of efficiency, voltage and current stress, and voltage gain in continuous conduction mode (CCM) of operation.

\section{Operation Principles and Topology Analysis of the Proposed Converter}

The modified PP-QZSC in Figure 2c follows the switching sequence shown in Figure 3.

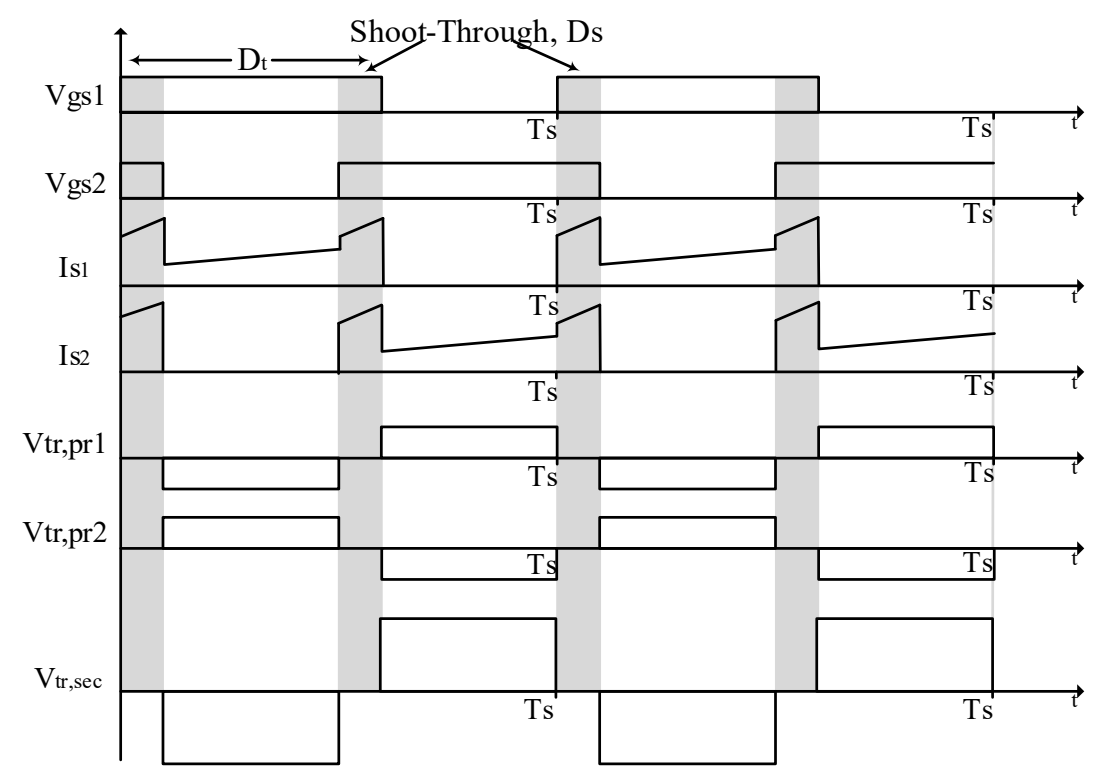

Figure 3. Equivalent circuits of the converters: (a) Full power QZSC, (b) Basic PPP QZSC, (c) Proposed PPP QZSC.

It should point out that in order to guarantee a good operation of the proposed converter, the duty cycle $D_{t}$ should be within $50 \%<D_{t}<75 \%$ and hence the shoot-through duty cycle $D_{s}$ is $D_{s}=2 D_{t}-1$. As by short circuiting the transformer magnetically the shoot through situation happens, the transformer design should be very accurate [22]. In this study the transformer magnetizing inductance $L_{M}$, is neglected.

Considering the sequence described in the figure, three modes of operation can be defined for modified PP-QZSC (Figure 2c). The equivalent circuits corresponding to these modes are shown in Figure 4. In the proposed converter the output voltage is the sum of the voltages at $C_{1}$ and $C_{4}$. Therefore, the output voltage can be determined as follows:

$$
\begin{aligned}
& V_{\text {out }}=V_{C_{1}}+V_{C_{4}} \\
& V_{C_{1}}=\frac{1-D_{s}}{1-2 D_{s}} V_{i n} \\
& V_{C_{4}}=\frac{2 n}{1-2 D_{s}} V_{i n}
\end{aligned}
$$

where, $V_{\text {out }}$ and $V_{\text {in }}$ is the output and input voltages and $D_{s}$ stands for shoot through duty cycle. Substituting (1) and (2) into (3) and based on $D_{t}$ or $D_{s}$, the converter voltage gain can be expressed as:

$$
\frac{V_{\text {out }}}{V_{\text {in }}}=\frac{2 n+1-D_{s}}{1-2 D_{s}}=\frac{2\left(n+1-D_{t}\right)}{3-4 D_{t}}
$$


where, $n$ is the transformer turns ratio and $D_{t}$ is the duty cycle of switches. The same analysis can be considered for basic PP-QZSC and FP- QZSC which is given by (5) and (6) respectively.

$$
\begin{gathered}
\frac{V_{\text {out }}}{V_{\text {in }}}=\frac{2 n+3-4 D_{t}}{3-4 D_{t}} \\
\frac{V_{\text {out }}}{V_{\text {in }}}=\frac{2 n}{3-4 D_{t}}
\end{gathered}
$$

Figure 5 shows the voltage gain versus duty cycle for similar transformer turn ratio, $n=1$. As it can be realized, the proposed converter with a slight difference, provides a higher voltage gain. This is translated into a lower voltage stress for all the elements, specifically for the voltage stress in the semiconductors. Moreover, the proposed converter is compared to other PP topologies such as: Boost, Full Bridge, and Flyback PPC. This figure shows the merit of PPP technique for impedance network converters.

The QZS network part of the circuit only processes two modes of operation: Shoot-through mode and non-Shoot-through mode. So, the inductor currents in steady state can be derived based on the following two modes of operation:

Shoot-through mode: In this stage the diode $D_{1}$ is turned off and the DC link terminals are magnetically short circuited, therefore the following equations referring to Figure $4 \mathrm{a}$ can be written:

$$
\begin{gathered}
i_{C 1}=-i_{\text {L2 }}-i_{\text {out }} \\
i_{C 2}=-i_{L 1}=-i_{\text {in }}
\end{gathered}
$$

where $i_{\text {in }}, i_{\text {out }}, i_{C}$, and $i_{L}$ are input, output, capacitor, and inductor currents respectively.

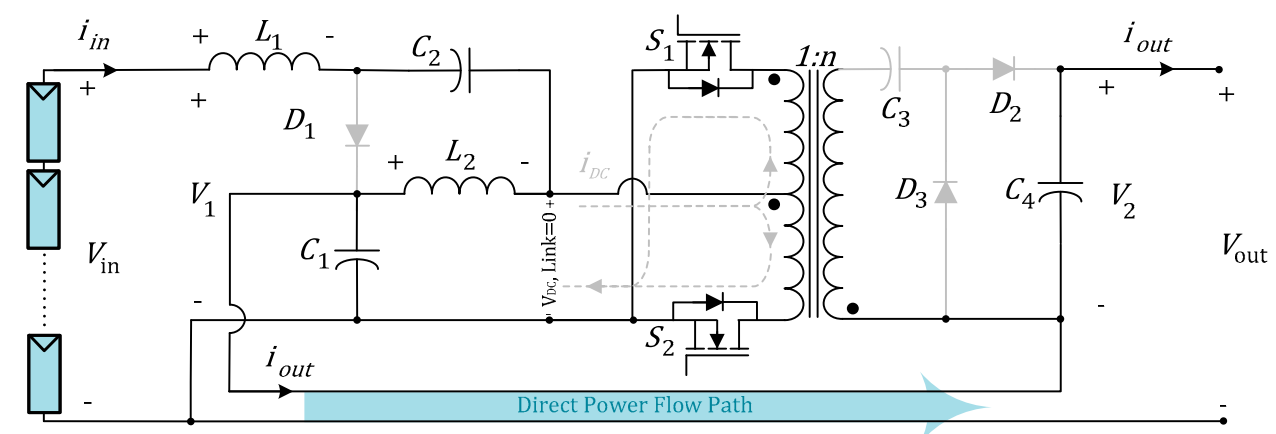

(a)

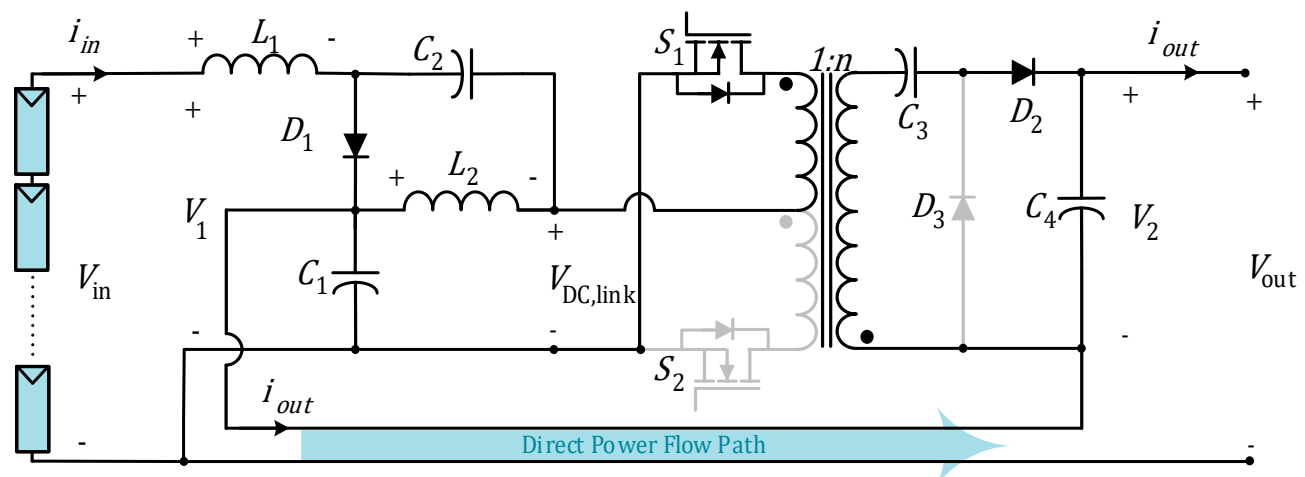

(b)

Figure 4. Cont. 


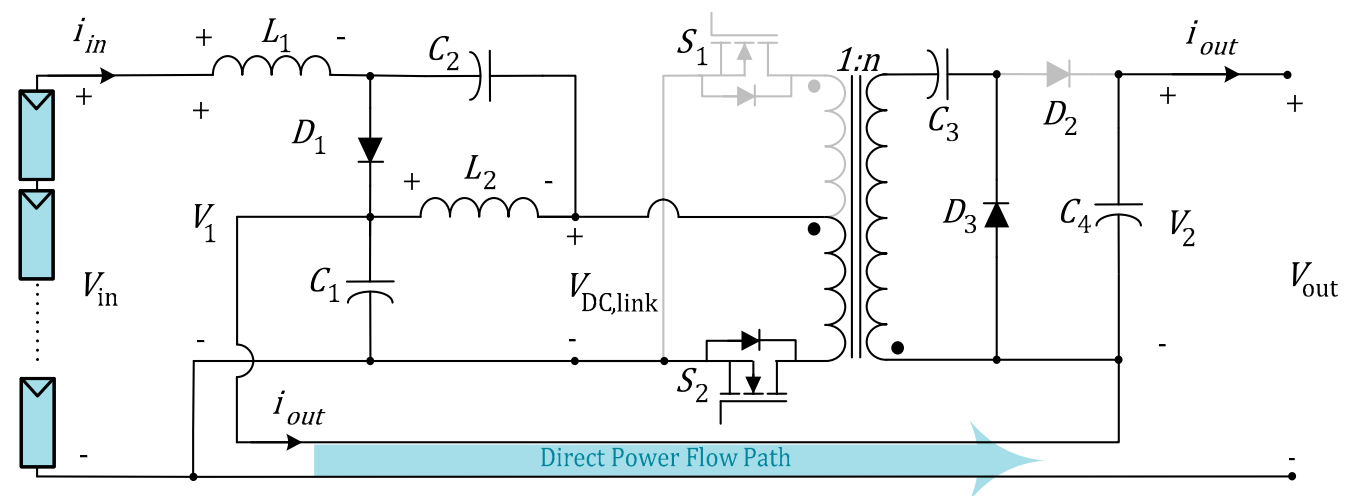

(c)

Figure 4. Operation modes of the proposed PPP QZSC: (a) Shoot-through mode, (b) Non-shoot-through and $S_{1}$ is ON, $S_{2}$ is off, (c) Non-shoot-through and $S_{2}$ is $\mathrm{ON}, S_{1}$ is off.

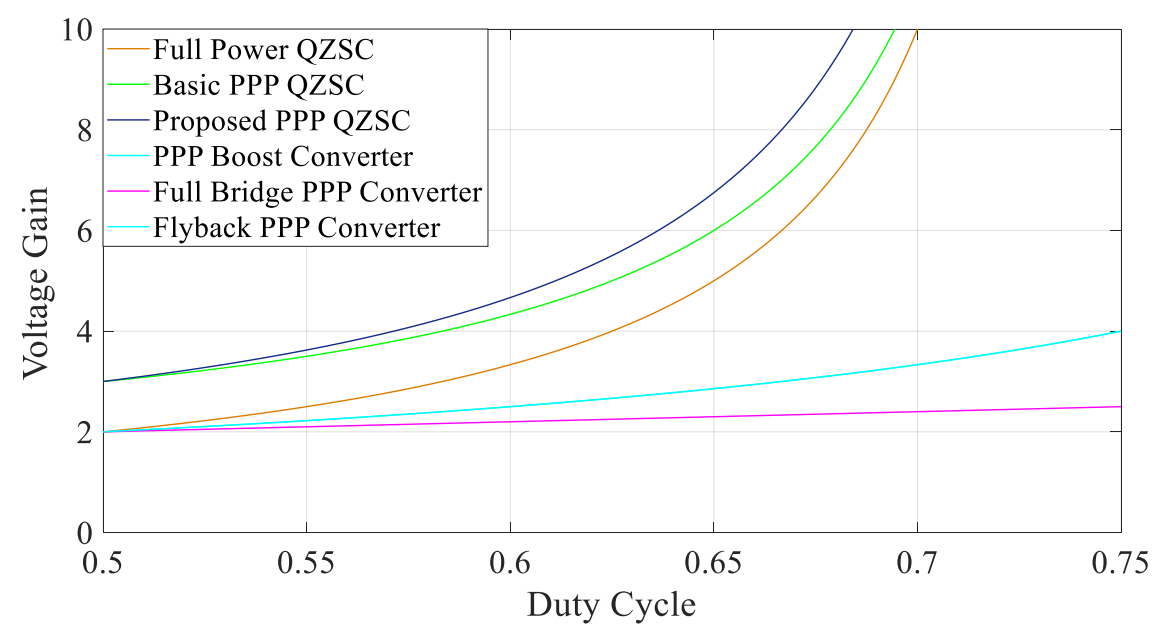

Figure 5. Voltage gain versus duty cycle for three discussed converters and PPP structures of Flyback, H-bridge, and Boost converters (Flyback and Boost have similar waveform).

Non-shoot-through mode: Based on Figure $4 \mathrm{~b}$ or Figure $4 \mathrm{c}$, the diode $D_{1}$ is turned on and inductors currents are induced to DC link terminals, so;

$$
\left\{\begin{array}{l}
i_{C_{1}}=i_{D_{1}}-i_{L_{2}}-i_{\text {out }} \\
i_{C_{2}}=i_{D_{1}}-i_{\text {in }}
\end{array}\right.
$$

where $i_{D_{1}}$ is the $D_{1}$ current. According to the capacitor Amp-second balance law and shoot through duty cycle, the inductor's steady state current can be calculated as:

$$
\left\{\begin{array}{l}
I_{L_{1}}=I_{\text {in }}=\frac{2 n+1-D_{s}}{1-2 D_{s}} \cdot \frac{V_{\text {out }}}{R_{\text {out }}}=\frac{2\left(n+1-D_{t}\right)}{3-4 D_{t}} \cdot \frac{V_{\text {out }}}{R_{\text {out }}} \\
I_{L_{2}}=I_{\text {in }}-I_{\text {out }}=\frac{2 n+D_{s}}{1-2 D_{s}} \cdot \frac{V_{\text {out }}}{R_{\text {out }}}=\frac{2 n+2 D_{t}-1}{3-4 D_{t}} \cdot \frac{V_{\text {out }}}{R_{\text {out }}}
\end{array}\right.
$$

\section{Comparison and Evaluation of Topologies}

In the following, three discussed converters are compared regarding several criteria in steady state operation. The averaged model of QZSC and PP-QZSC is discussed in [26].

\subsection{Voltage and Current Stress Analysis}

The voltage and current stress of the semiconductor devices are shown in Table 1. Current stress equations of the converters are identically except for $D_{1}$ current stress, so overall the modified 
PP-QZSC has lower current stress compared to others. Also the voltage stress of the modified PP-QZSC is reduced compared to FP-QZSC and basic PP-QZSC. Both the basic and the modified PP-QZSC have less current and voltage stresses compared to FP-QZSC. Figure 6 illustrates a comparison of the switch's voltage stress as a ratio of input voltage based on the converter voltage gain. From this figure it can be concluded that having less voltage stress in the switches results in lower switch built in conducting resistance. Also, the voltage stress of other elements such as diodes are reduced. Lower voltage stress results in lower power rating of the elements, for instance low power rated passive element like capacitor. Generally, reduced voltage and current stress of the elements, specifically active elements, can be effective for enhancing the converter's cost.

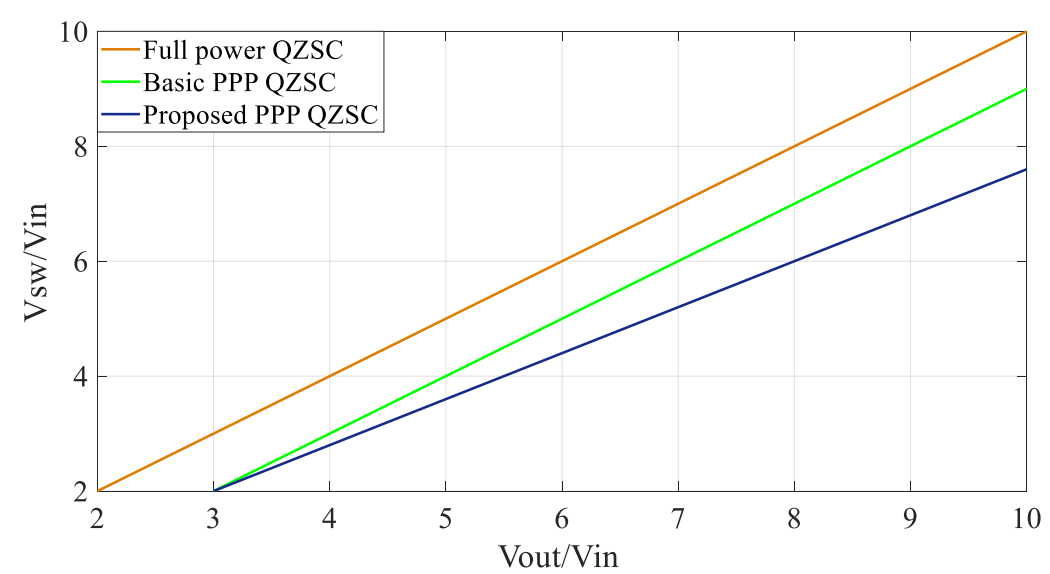

Figure 6. MOSFET voltage stress/input voltage versus voltage gain for FP-QZSC, basic PP-QZSC, and modified PP-QZSC (Transformer turn ratio = 1).

\subsection{Element Design}

The full bridge, half bridge, and push-pull switching topologies help the voltage and current stress to be reduced compared to single switching topologies [21]. The steady state analysis of inductors current ripples and capacitors voltage ripples indicates the size of passive elements of the converters, therefore;

$$
\begin{gathered}
\left\{\begin{array}{l}
L_{1}=\frac{2\left(2 D_{t}-1\right)\left(1-D_{t}\right)}{4 n f_{s}} \cdot \frac{V_{\text {out }}}{\Delta I_{11}} \\
L_{2}=\frac{2\left(2 D_{t}-1\right)\left(1-D_{t}\right)}{4 n f_{s}} \cdot \frac{V_{\text {out }}}{\Delta I_{L_{2}}}
\end{array}\right. \\
\left\{\begin{array}{l}
C_{1}=\frac{\left(n+1-D_{t}\right)\left(2 D_{t}-1\right)}{\left(3-4 D_{t}\right) f_{s} R_{\text {out }}} \cdot \frac{V_{\text {out }}}{\Delta V_{C_{1}}} \\
C_{2}=\frac{\left(n+1-D_{t}\right)\left(2 D_{t}-1\right)}{\left(3-4 D_{t}\right) f_{s} R_{\text {out }}} \cdot \frac{V_{\text {out }}}{\Delta V_{C_{2}}} \\
C_{3}=\frac{4 n+1}{2 n f_{s} R_{\text {out }}} \cdot \frac{V_{\text {out }}}{\Delta V_{C_{3}}} \\
C_{4}=\frac{D_{t}}{2 f_{s} R_{\text {out }}} \cdot \frac{V_{\text {out }}}{\Delta V_{C_{4}}}
\end{array}\right.
\end{gathered}
$$

where, $\Delta i_{L}$ is the inductor current ripple, $\Delta V_{C}$ is the capacitor voltage ripple and $f_{s}$ is the switching frequency. The output voltage ripple for FP-QZSC and basic PP-QZSC are $\Delta V_{C_{4}}$ but for the modified PP-QZSC is the summation of $\Delta V_{C_{1}}$ and $\Delta V_{C_{4}}$. 
Table 1. Voltage and current stress comparison.

\begin{tabular}{|c|c|c|c|}
\hline \multicolumn{2}{|c|}{ Converter } & Voltage Stress & Current Stress \\
\hline Switches & $\begin{array}{c}\text { Full Power QZSC [22] } \\
\text { Basic PPP QZSC } \\
\text { Proposed PPP QZSC }\end{array}$ & $\begin{array}{c}\frac{1}{n} \cdot V_{\text {out }} \\
\frac{2}{2 n-1-2 D_{s_{1}}} V_{\text {out }} \\
\frac{2}{2 n+1-D_{s_{2}}} V_{\text {out }}\end{array}$ & $\begin{array}{c}\frac{2 n}{1-2 D_{s}} \cdot \frac{V_{\text {out }}}{R_{\text {out }}} \\
\frac{2 n}{1-2 D_{s_{1}}} \cdot \frac{V_{\text {out }}}{R_{\text {out }}} \\
\frac{4 n+1}{2\left(1-D_{s_{2}}\right)} \cdot \frac{V_{\text {out }}}{R_{\text {out }}}\end{array}$ \\
\hline Diode $D_{1}$ & $\begin{array}{c}\text { Full Power QZSC } \\
\text { Basic PPP QZSC } \\
\text { Proposed PPP QZSC }\end{array}$ & $\begin{array}{c}\frac{1}{2 n} \cdot V_{\text {out }} \\
\frac{1}{2 n+1-2 D_{s_{1}}} V_{\text {out }} \\
\frac{1}{2 n+1-D_{s_{1}}} V_{\text {out }}\end{array}$ & $\begin{array}{c}\frac{2 n V_{\text {out }}}{\left(1-2 D_{s_{s}}\right)\left(1-D_{s}\right) R_{\text {out }}} \\
\frac{2 n V_{\text {out }}}{\left(1-2 D_{s_{1}}\right)\left(1-D_{s_{1}}\right) R_{\text {out }}} \\
\frac{\left(2 n+1-D_{s_{2}}\right) V_{\text {out }}}{\left(1-2 D_{s_{2}}\right)\left(1-D_{s_{2}}\right) R_{\text {out }}}\end{array}$ \\
\hline Diode $D_{2} \& D_{3}$ & $\begin{array}{c}\text { Full Power QZSC } \\
\text { Basic PPP QZSC } \\
\text { Proposed PPP QZSC }\end{array}$ & $\begin{array}{c}V_{\text {out }} \\
\frac{2 n}{2 n+2-2 D_{s_{1}}} V_{\text {out }} \\
\frac{2 n}{2 n+1-D_{s_{2}}} V_{\text {out }}\end{array}$ & $\begin{array}{c}\frac{2}{1-2 D_{s}} \cdot \frac{V_{\text {out }}}{R_{\text {out }}} \\
\frac{2}{1-2 D_{s_{1}}} \cdot \frac{V_{\text {out }}}{R_{\text {out }}} \\
\frac{2 n+D_{s_{2}}}{n\left(1-2 D_{s_{2}}\right)} \cdot \frac{V_{\text {out }}}{R_{\text {out }}}\end{array}$ \\
\hline & verter & Inductor $L_{1}$ & Inductor $L_{2}$ \\
\hline Current Stress & $\begin{array}{c}\text { Full Power QZSC } \\
\text { Basic PPP QZSC } \\
\text { Proposed PPP QZSC }\end{array}$ & $\begin{array}{c}\frac{2}{1-2 D_{s}} \cdot \frac{V_{\text {out }}}{R_{\text {out }}} \\
\frac{2}{1-2 D_{s 1}} \cdot \frac{V_{\text {out }}}{R_{\text {out }}} \\
\frac{2 n+1-D_{\text {s2 }}}{1-2 D_{s_{2}}} \cdot \frac{V_{\text {out }}}{R_{\text {out }}}\end{array}$ & $\begin{array}{l}\frac{2}{1-2 D_{s}} \cdot \frac{V_{\text {out }}}{R_{\text {out }}} \\
\frac{2}{1-2 D_{s_{1}}} \cdot \frac{V_{\text {out }}}{R_{\text {out }}} \\
\frac{2 n+D_{s_{2}}}{1-2 D_{s_{2}}} \cdot \frac{V_{\text {out }}}{R_{\text {out }}}\end{array}$ \\
\hline
\end{tabular}

\subsection{Comparison}

In terms of comparison, some parameters have been considered such as voltage gain, voltage and current stress, voltage ripple of capacitors, current ripple of inductors, power losses, transformer turn ratio, number of used elements, and efficiency. Therefore, some non-idealities of elements such as: Inductor resistance, transformer resistance, switch built in conducting resistance, and diode conducting voltage drop are considered. Also, converter no-load power loss which is caused by transformer or inductor core loss has been considered as a constant factor of output power. Other non-idealities such as capacitor equivalent series resistance (ESR) or diode resistance are neglected. Table 2 shows the converters specifications and the amount of non-ideal elements which has been considered in terms of simulation comparison.

Table 2. Prototype and Simulation parameters.

\begin{tabular}{ccc}
\hline Parameters & Symbols & Value/Part no. \\
\hline Output Voltage & $V_{\text {out }}$ & $90 \mathrm{~V}$ \\
Input Voltage & $V_{\text {in }}$ & $20 \mathrm{~V}$ \\
Switching Frequency & $f_{s}$ & $40 \mathrm{kHz}$ \\
Duty Cycle & $D_{t}$ & 0.6 \\
Transformer turn ratio & $n$ & $1: 1: 1$ \\
Primary and secondary resistance & $R_{w p}, R_{w s}$ & $0.01 \Omega$ \\
Inductance & $L_{1}, L_{2}$ & $200 \mu \mathrm{H}$ \\
Inductor resistance & $R_{L_{1}}, R_{L_{2}}$ & $0.01 \Omega$ \\
Diode Forward Voltage & $V_{d}$ & $0.98 \mathrm{~V}$ \\
capacitance & $C_{1}, C_{2}, C_{3}, C_{4}$ & $100 \mu \mathrm{F}$ \\
Switch on resistance & $R_{o n}$ & $0.18 \Omega$ \\
Switch & $S_{1}, S_{2}$ & IRF640N \\
\hline
\end{tabular}

\subsection{Voltage Gain Comparison}

The effect of non-idealities is translated into power losses increase and reduction of the output voltage that results in higher duty cycle for a determined value of input and output voltage. Figure 7 illustrates the output voltage comparison versus duty cycle while the input voltage is the same. As 
it can be seen, the required duty cycle for the proposed PPP converter at a specific output voltage is lower than in other converters.

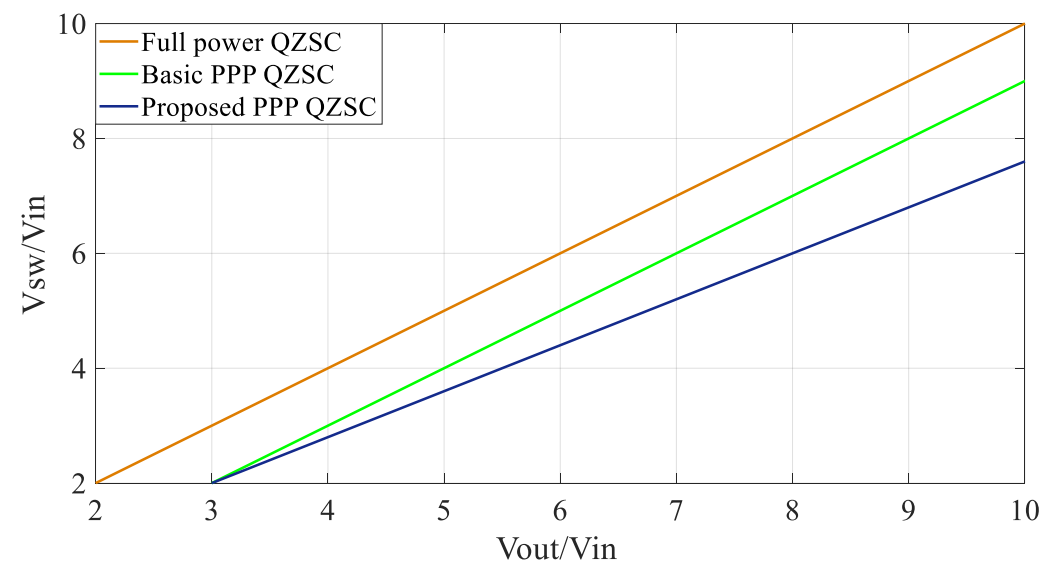

Figure 7. The effect of non-idealities on output voltage waveform versus duty cycle for the three discussed converters.

\subsection{Losses Comparison}

Figure 8 shows the conducting dissipation power comparison between FP-QZSC, basic PP-QZSC, and the modified PP-QZSC. Both presented PPCs have lower power losses compared to FP-QZSC.

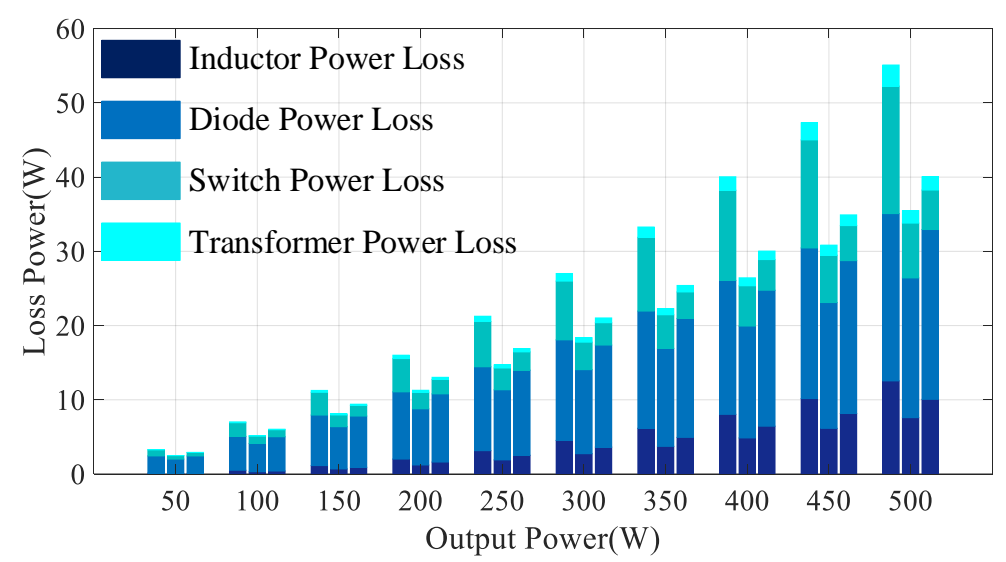

Figure 8. Power Loss Comparison: Left bar) Full power QZSC, Middle bar) Basic PPP QZSC, Right bar) Proposed PPP QZSC.

The efficiency difference between the basic and the proposed PP structures is related to current difference passing through $L_{1}$. The power losses difference between the basic PP-QZSC and the modified PP-QZSC, where the basic converter dissipates less power, as this parameter is highly dependent on the value of $L_{1}$ and $D_{1}$. These two parameters are the structural difference between the presented converters. In the QZSC network of the modified PP-QZSC, $L_{1}$ and $D_{1}$ currents are equal to $I_{\text {in }}$ but in the basic PP-QZSC this value is lower, being $I_{i n}-I_{\text {out }}$ the overall current that go through the circuit. Other elements performances are almost similar in the basic PP-QZSC and the modified PP-QZSC, because they handle $I_{\text {in }}-I_{\text {out }}$ which give rise to similar power losses. Therefore, in proposed model these elements process the whole input power which in this case causes higher losses than in the basic converter. In terms of power losses, the switching losses are also considered. Based on parasitic elements, which are mentioned before and referring to Tables 1 and 2, the power losses of the inductors, diodes, switches, and transformer are given by (12), (13), (14), and(15) respectively. These equations are calculated based on switching duty cycle, $D_{t}$. In order to compute the losses, RMS values of each current are calculated. With a small approximation, diodes, switches, and transformer current ripples 
are considered to be inductor current ripple. The inductors power losses value is based on their RMS current, which is calculated as follows,

$$
\begin{gathered}
P_{L}=R_{L_{1}} I_{L_{1}, r m s}{ }^{2}+R_{L_{2}} I_{L_{2}, r m s}{ }^{2} \\
\left\{\begin{array}{c}
I_{L_{1}, r m s}=I_{L_{1}, a v g} \sqrt{1+\frac{1}{3}\left(\frac{\Delta i}{2 I_{L_{1}, a v g}}\right)} \\
I_{L_{2}, r m s}=I_{L_{2}, a v g} \sqrt{1+\frac{1}{3}\left(\frac{\Delta i}{2 I_{L_{2}, a v g}}\right)}
\end{array}\right.
\end{gathered}
$$

where $P_{L}, I_{L_{1}, r m s}, I_{L_{2}, r m s}$, and $\Delta i$ are the overall inductor's losses, $L_{1}$ and $L_{2}$ the average current and current ripple which can be obtained in (14), respectively. Also, diodes and switches power losses are calculated based their current RMS values, so

$$
P_{D}=\left(I_{D_{1}, a v g}+I_{D_{2}, a v g}+I_{D_{3}, a v g}\right) V_{d}
$$

$P_{D}$ is the sum of diodes conduction loss and is calculated based on the average current. Also, $I_{D_{1}, r m s}, I_{D_{2}, r m s}$, and $I_{D_{3}, r m s}$ are:

$$
\left\{\begin{array}{l}
I_{D_{1}, a v g}=\frac{2 n+1-D_{s}}{1-2 D_{s}} \cdot \frac{V_{\text {out }}}{R_{\text {out }}} \\
I_{D_{2}, a v g}=I_{D_{3}, a v g} \frac{\left(1-D_{s}\right)\left(2 n+D_{s}\right)}{2 n\left(1-2 D_{s}\right)} \cdot \frac{V_{\text {out }}}{R_{\text {out }}}
\end{array}\right.
$$

$P_{S(c o n d)}$ are the conduction losses in the switches $\left(S_{1}\right.$ and $\left.S_{2}\right) . I_{S, r m s}($ Cond) is the RMS value of the current at the switch and is calculated as:

$$
\left\{\begin{array}{c}
P_{S_{1}(\text { Cond })}=P_{S_{2}(\text { Cond })}=\frac{1}{2} P_{S(\text { cond })} \\
P_{S(\text { cond })}=2 R_{\text {on }} I_{S, r m s}(\text { Cond })
\end{array}\right.
$$

$P_{S(c o n d)}$ are the conduction losses of the switches $\left(S_{1}\right.$ and $\left.S_{2}\right)$. Likewise, $I_{S, r m s}$ is the RMS value of the current at the switch and it can be calculated as:

$$
I_{s, r m s}=\sqrt{\frac{11-2 D_{t}}{24} \Delta i^{2}+\left(2 D_{t}-1\right) I_{1}^{2}+\left(1-D_{t}\right) I_{2}^{2}}
$$

where $I_{1}$ and $I_{2}$ are the $D_{s} T_{s}$ and $\left(D_{t}-D_{s}\right) T_{s}$ time intervals average currents, as it can be concluded from Figure 3. The transformer's primary and secondary windings losses are determined according to the switches and diode $D_{2}$ and $D_{3}$ currents, respectively. According to Figure $4 \mathrm{a}, \mathrm{b}$ the transformer primary windings conduction is based on switches turn on time interval, $D_{t} T_{s}$ and the secondary winding is calculated in $\left(1-D_{s}\right) T_{s}$. Therefore;

$$
\begin{aligned}
& P_{\text {winding }}=P_{\text {wind,pri1 }}+P_{\text {wind,pri2 } 2}+P_{\text {wind, sec }} \\
& \left\{\begin{array}{l}
P_{\text {wind }, \text { pri1 } 1}=P_{\text {wind,pri2 }}=R_{w} I_{S, r m s,(\text { Cond })}{ }^{2} \\
P_{\text {wind,sec }}=R_{w} I_{D 2, r m s}{ }^{2}
\end{array}\right.
\end{aligned}
$$

$P_{\text {winding }}$ is the sum of the transformer primary and secondary power losses. The switching power loss $\left(P_{S(\text { switching) })}\right)$ due to non-ideal turn-on and turn-off is illustrated by (18).

$$
\left\{\begin{array}{l}
P_{S(\text { switching })}=2\left(\alpha_{o n}+\alpha_{o f f}\right)\left(V_{s w} I_{s w}\right) f_{s w} \\
\alpha_{o n}=\alpha_{o f f}=0.5\left(\tau_{\text {rise }}+\tau_{\text {fall }}\right)
\end{array}\right.
$$

$\alpha_{o n}$ and $\alpha_{o f f}$ are turn on and turn off switching times respectively which can be found in the datasheet. Also $V_{s w}$ and $I_{s w}$ are the average voltage and current stress of the switches, which can be obtained from Table 1. Figure 9 shows the MOSFET switches power loss comparison based on (17) and (18), which the proposed converter has less switch power dissipation. 


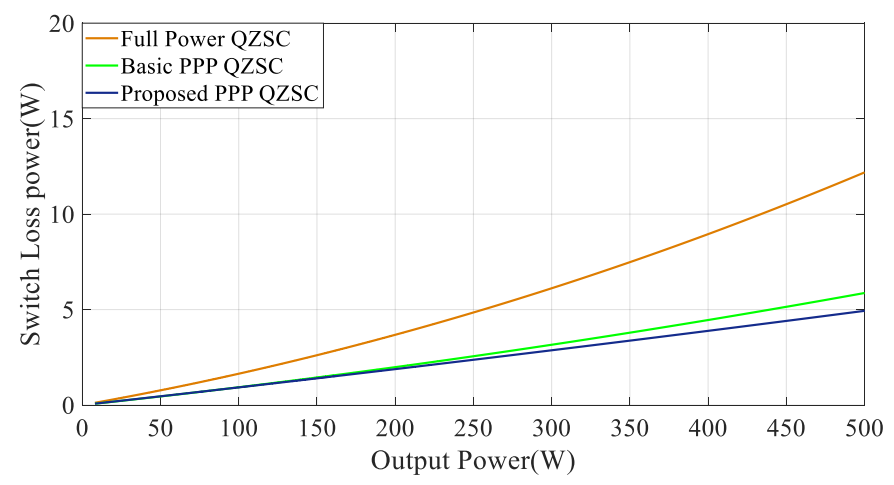

Figure 9. Switch power loss versus output power for the three discussed converters.

\subsection{Efficiency Comparison}

Integrating PPP technique into any converter does not necessarily mean an improvement in the efficiency [1]. In this case integrating PPP technique improved both basic proposed models compared to full power converter. However, the proposed converter efficiency is lower than basic structure. The structural difference between basic and proposed converters has been mentioned which results in efficiency difference as well. Efficiency of the proposed model highly depends on operating points and transformer turn ratio, which in some cases the modified PP-QZSC efficiency can be improved compared to the basic model. The relationship between these three converters efficiencies which have been listed in Table 3. Since the QZSC efficiency $\eta_{Q 1}$ is always smaller than one, the overall efficiencies of the basic PP-QZSC and the modified PP-QZSC are higher than the FP-QZSC. If the individual converter efficiencies are similar, the relation of converters efficiencies are $\eta_{S 3}>\eta_{S 2}>\eta_{S 1}$ which is shown in Figure 10. Moreover, the full power converter duty cycle is higher than the other two converters. Also, $V_{\text {out }} / V_{C 4}$ ratio in the modified PP-QZSC is limited to a range between 1.25 and 1.5 because of switching duty cycle which is a range between $50 \%$ to $75 \%$. Individual system efficiency of the proposed PPP system, $\eta_{\mathrm{Q} 3}$ is dependent on this ratio. If $V_{\text {out }} / V_{\mathrm{C} 4}$ gets larger, $\eta_{\mathrm{Q} 3}$ gets lower, therefore $\eta_{\mathrm{S} 3}$ is always lower than one. Figure 11 shows the efficiency comparison based on the output power.

Table 3. Efficiency comparison of Full power, basic PPP, and proposed PPP QZSC.

\begin{tabular}{cccc}
\hline Converter & $\begin{array}{c}\text { Individual Converter } \\
\text { Output Voltage }\end{array}$ & $\begin{array}{c}\text { Individual } \\
\text { Converter Efficiency }\end{array}$ & System Efficiency \\
\hline Full power QZSC & $V_{\text {out }}$ & $\eta_{Q_{1}}$ & $\eta_{S_{1}}=\eta_{Q_{1}}$ \\
\hline Basic PPP QZSC & $V_{\text {out }}-V_{\text {in }}$ & $\eta_{Q_{1}}$ & $\eta_{S_{2}}=\frac{V_{\text {out }}}{V_{C_{4}}+\eta_{Q_{2}} \cdot V_{\text {in }}} \cdot \eta_{Q_{2}}$ \\
\hline Proposed PPP QZSC & $V_{\text {out }}-V_{C_{1}}$ & $\eta_{Q_{3}}$ & $\eta_{S_{3}}=\frac{V_{\text {out }}}{V_{C_{4}}} \cdot \eta_{Q_{3}}$ \\
\hline
\end{tabular}

It should be noticed that, the experimental efficiency curve in 22 , shows that maximum efficiency of FP-QZSC can go beyond $97 \%$ which is different from our measurement. The efficiency curve of two converters may be compared only if all the conditions are the same. The parameters which affect the converter efficiency are: MOSFET conduction resistance and switching loss, diode forward voltage, winding resistance, and converter operation points. In two prototypes of the converter, these values may differ and therefore different efficiency values can be calculated. 


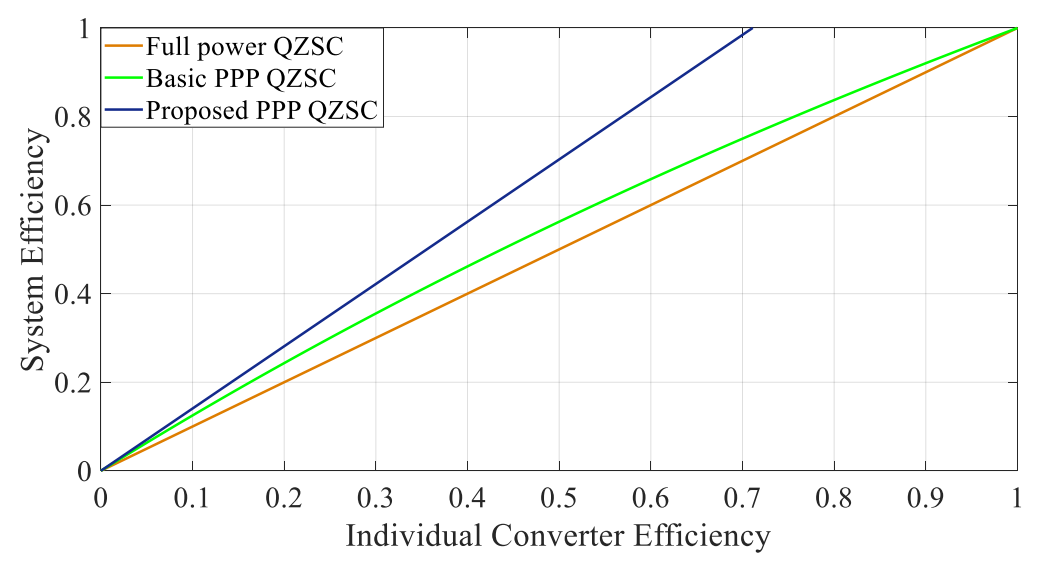

Figure 10. System efficiency versus individual converter efficiency.

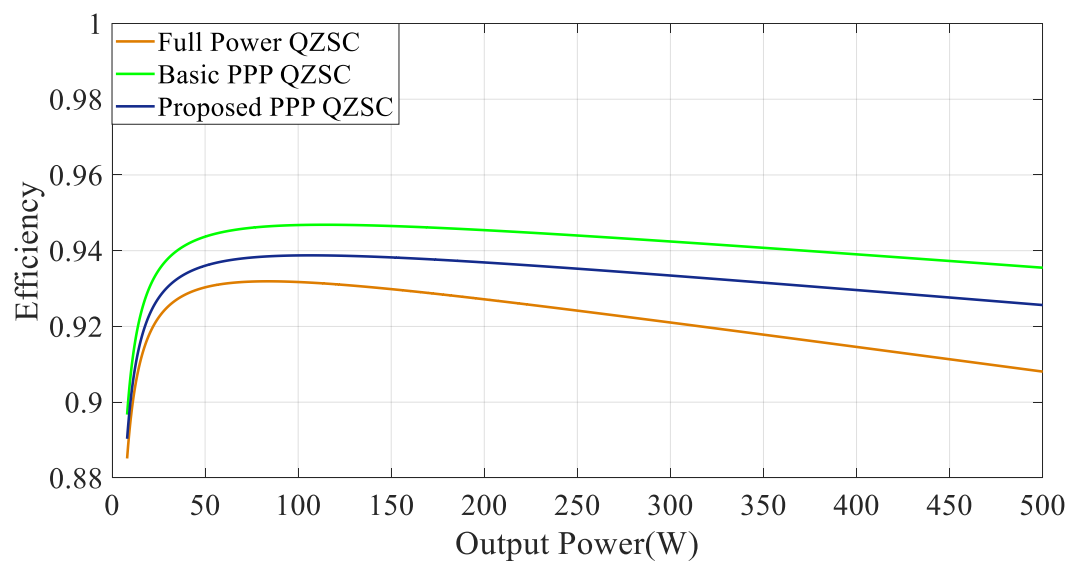

Figure 11. Efficiency versus output power for the three discussed converters.

\section{Simulation and Experimental Results and Discussion}

The laboratory low power $200 \mathrm{~W}$ prototype of the proposed converter, shown in Figure 12, has been built to validate the theoretical analysis and simulation results. The prototype component values are shown in Table 2. In this section the simulation results and experimental results are shown and compared.

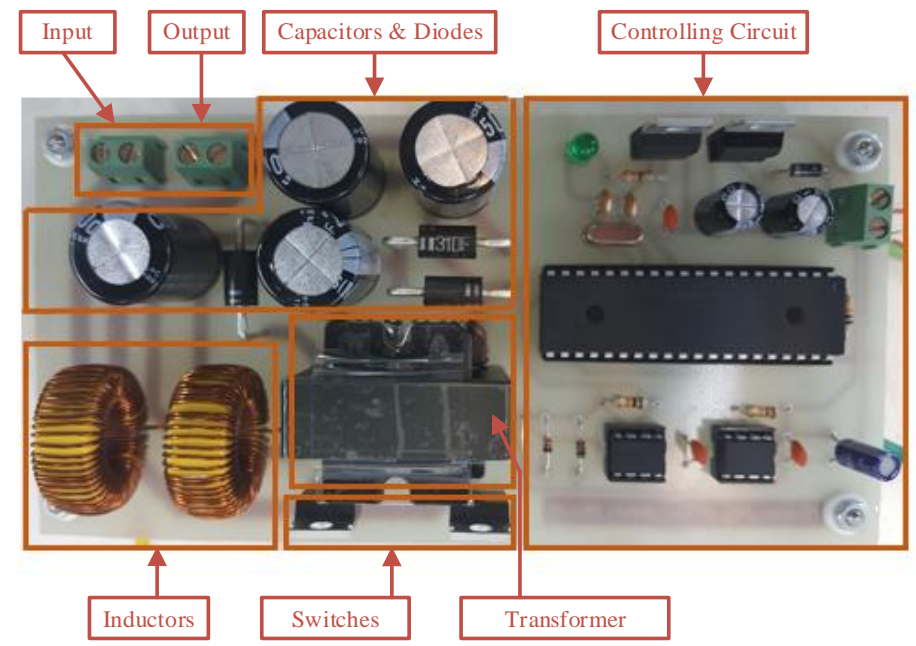

Figure 12. Laboratory prototype of the proposed converter. 
The switching gate signals for two switches are shown in Figure 13. In order to generate the desired output voltage, the switching and shoot though duty cycles are adjusted to $D_{t}=0.6$ and $D_{s}=0.2$ (according to (4)). The switching frequency is $40 \mathrm{kHz}$. All the experimental tests were conducted under CCM operation of the converter, as DCM does not represent a representative operating point. Comparing simulation and experimental results it can be seen that both match quite well. On the other hand, considering two separate shoot through time intervals (equals to $0.1 T_{s}$ ) during a switching cycle, the voltage ripple of $C_{1}$, and $C_{2}$ have a frequency equals to $2 f_{s}$ (Figure $14 \mathrm{c}, \mathrm{d}$ ). The frequency voltage ripple of $C_{3}$ and $C_{4}$ are the same as $f_{s}$ (Figure 14e,f). The experimental output voltage waveform is also shown in Figure 14a. As mentioned before, the output voltage ripple is the sum of $C_{1}$ and $C_{4}$ voltage ripples, which can be seen in Figure 14b.

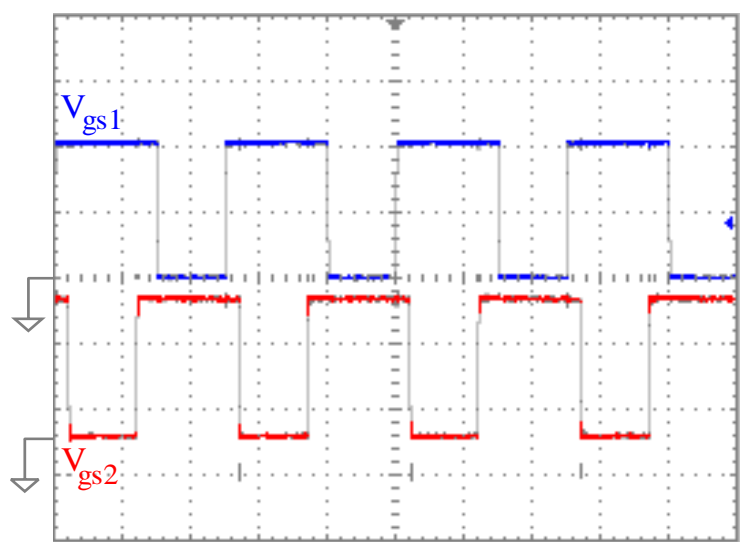

Figure 13. Switch gate signals $S_{1}$ and $S_{2}($ Volt $/$ div $=5 \mathrm{~V}$, Time $/$ div $=10 \mu \mathrm{s}) . D_{\mathrm{t}}=0.6$ and $D_{\mathrm{s}}=0.2$.

The waveforms of $I_{L_{1}}$ and $I_{L_{2}}$ are shown in Figure 15. The small current ripples insure the CCM operation of the converter. The only difference between the two current waveforms is that the $I_{L_{2}}$ is less than inductor $I_{L_{1}}$ as $I_{L_{2}}=I_{L_{1}}-I_{\text {out }}$. The experimental and simulation results for transformer primary and secondary voltages are shown in Figure 16. The primary and secondary voltage during shoot through mode is zero which shows the magnetically short circuit of the transformer. In order to compare the performance of the three discussed converters, three converters are made and several tests are done in different operating modes.

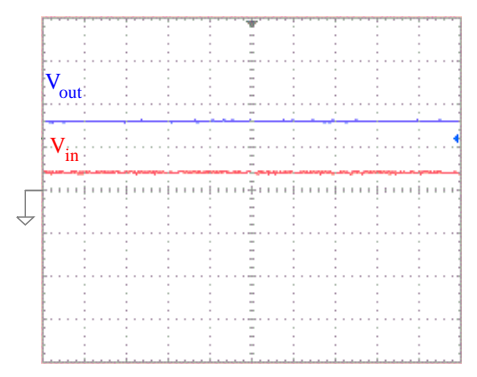

(a)

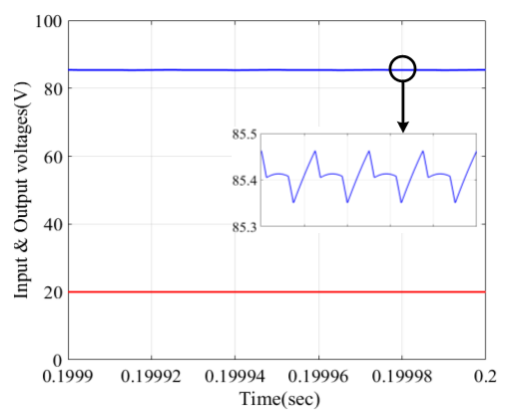

(b)

Figure 14. Cont. 


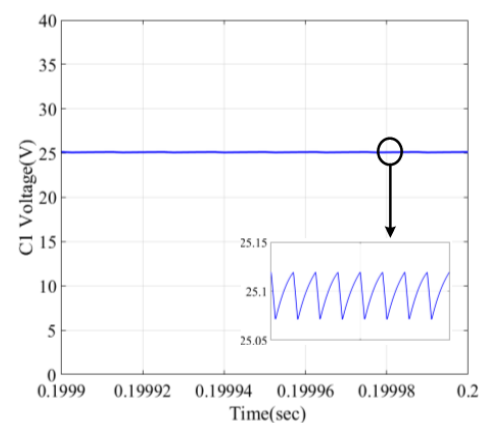

(c)

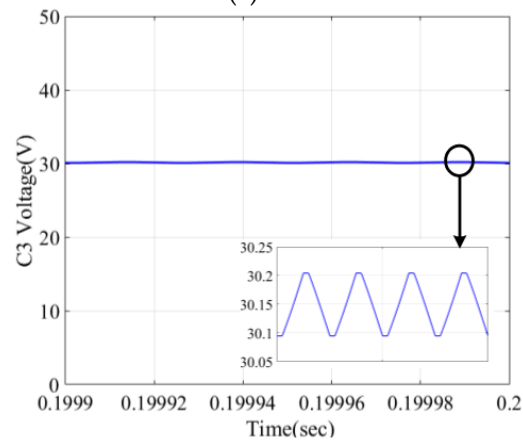

(e)

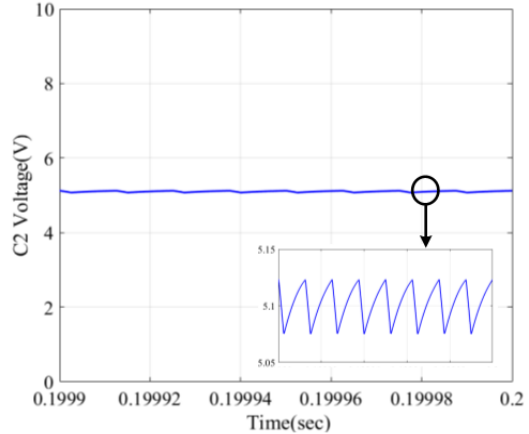

(d)

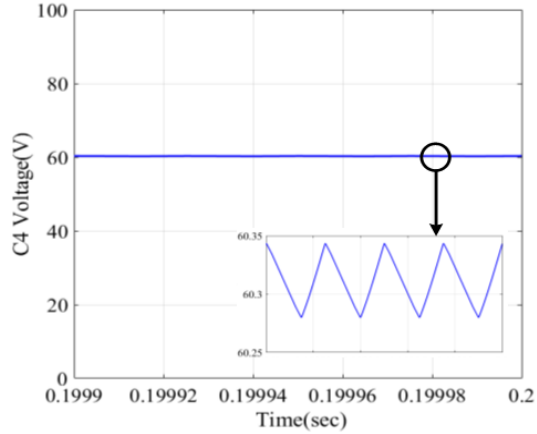

(f)

Figure 14. Experimental and simulation result waveforms: (a) Input and output voltage (Volt/div $=50 \mathrm{~V}$, Time/div $=10 \mu \mathrm{s})$, (b) Input and output voltage (c) Capacitor $C_{1}$ voltage, (d) Capacitor $C_{2}$ voltage, (e) Capacitor $C_{3}$ voltage and (f) Capacitor $C_{4}$ voltage.

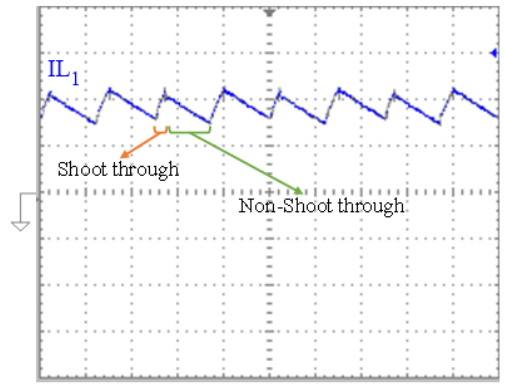

(a)

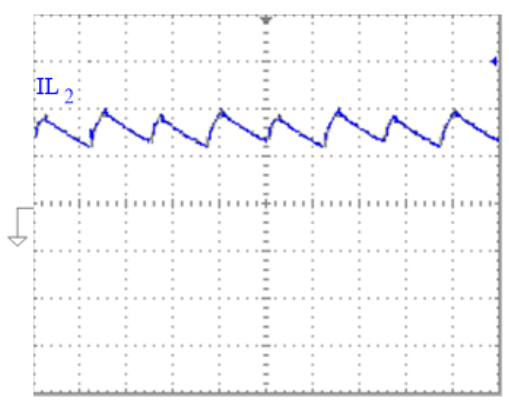

(c)

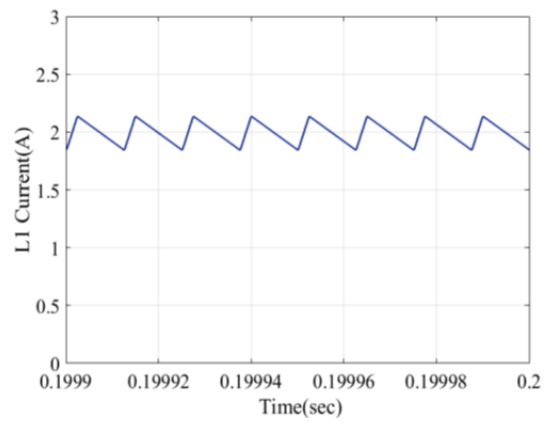

(b)

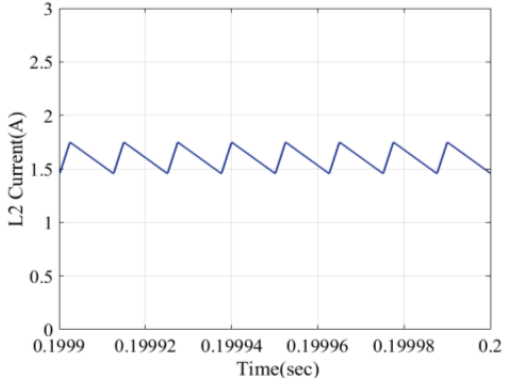

(d)

Figure 15. Simulation and experimental results for inductor currents: (a) experimental results for $I_{L_{1}}(\mathrm{Amp} / \mathrm{div}=1 \mathrm{~A}$, Time/div $=10 \mu \mathrm{s}),(\mathbf{b})$ simulation results for $I_{L_{1}},(\mathbf{c})$ experimental results for $I_{L_{2}}$ $($ Amp $/$ div $=1 \mathrm{~A}$, Time/div $=10 \mu \mathrm{s})$ and $(\mathbf{d})$ simulation results for $I_{L_{2}}$. 


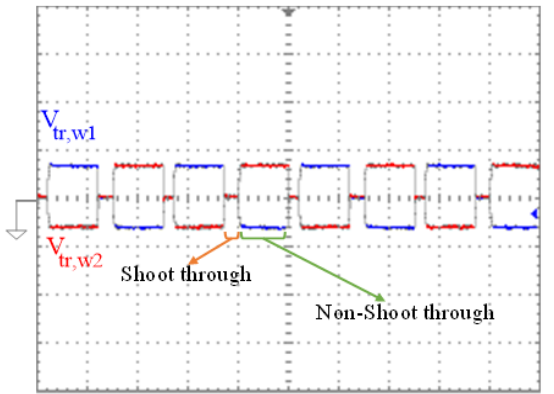

(a)

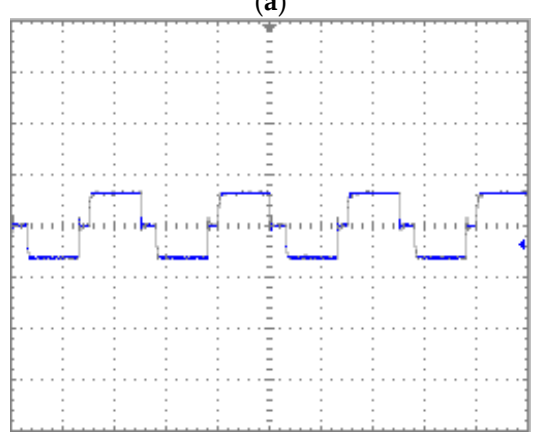

(c)

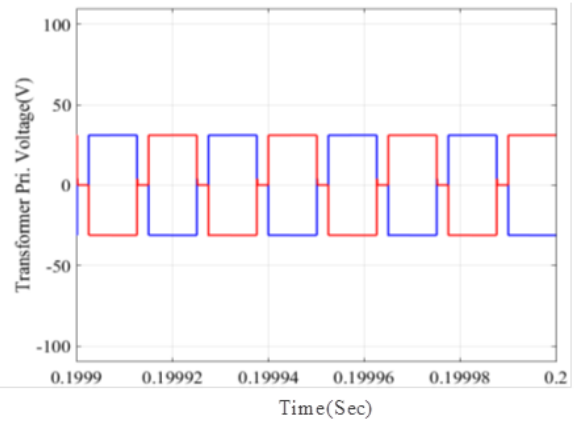

(b)

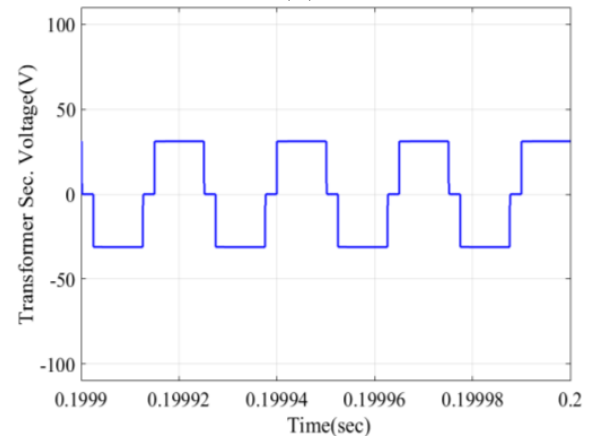

(d)

Figure 16. Simulation and experimental results for inductor currents: (a) experimental results for $I_{L_{1}}(\mathrm{Amp} / \mathrm{div}=1 \mathrm{~A}$, Time/div $=10 \mu \mathrm{s})$, (b) simulation results for $I_{L_{1}},(\mathbf{c})$ experimental results for $I_{L_{2}}$ $(\mathrm{Amp} / \mathrm{div}=1 \mathrm{~A}$, Time $/ \mathrm{div}=10 \mu \mathrm{s})$ and $(\mathbf{d})$ simulation results for $I_{L_{2}}$.

In Figure 17, the efficiency of the converters for different input voltages with constant switching duty cycle of 0.6 are sketched also compared with simulation resulted efficiency. The result shows higher efficiency of the basic PP-QZSC as predicted in Section 3. As discussed before, the semiconductor loss is lower which result in a smaller cooling system and improves the reliability of the system.

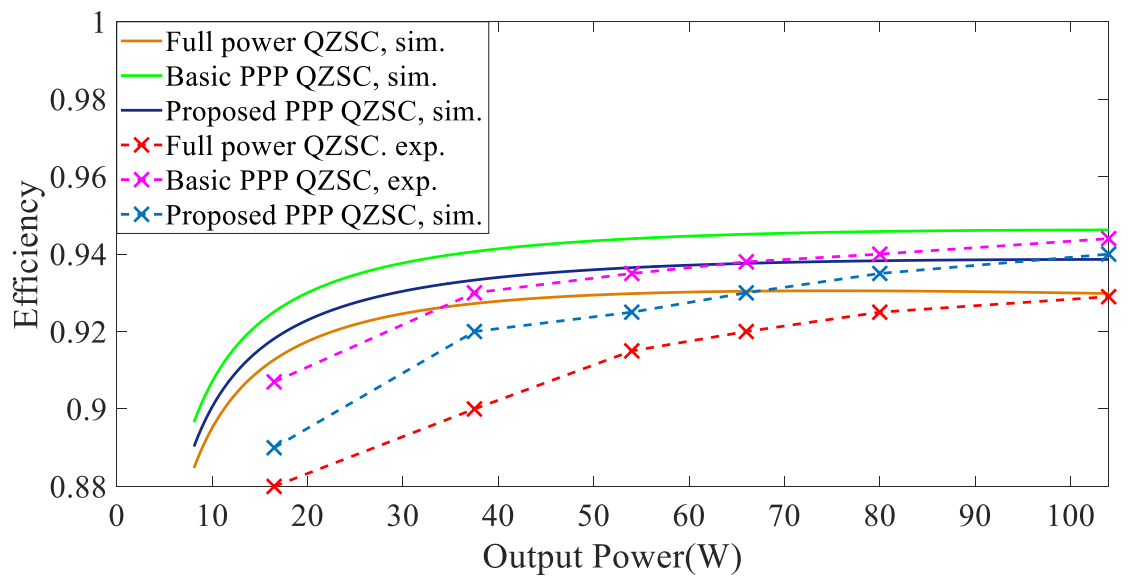

Figure 17. Experimental result for efficiency comparison of the three discussed converters.

\section{Conclusions}

This paper presents a modified QZSC using PPP technique. Compared to full power converter, partial power converter shows higher efficiency and lower voltage and current stress. Although the modified PP-QZSC had a rather lower efficiency by 1\%, but the voltage stress of the switches decrease by $25 \%$. High boost capability, lower voltage and current stress, improved efficiency and lower cost considering small duty cycle, and small turn ratio of the transformer are the proposed and 
basic PPP converters features. Higher boosting mode and reduced voltage stress are the proposed PPP QZSC advantages compared to basic PPP structure. The operating performance of the proposed converter was simulated and experimentally tested to validate the theoretical analysis. Due to lower power handled by the PPP converters, which is a remarkable feature, and considering the results and performance obtained, the proposed converter is promising to be used in PV systems, as a partial power inverter would give rise to a lower cost and size of the power processing stage.

Author Contributions: All persons who meet authorship criteria are listed as authors, and all authors certify that they have participated sufficiently in the work to take public responsibility for the content, including participation in the concept, design, analysis, writing, or revision of the manuscript. Furthermore, each author certifies that this material or similar material has not been and will not be submitted to or published in any other publication before its appearance in the Applied Sciences, MDPI. All in all, the contribution of all authors is almost equal.

Funding: This research received no external funding.

Conflicts of Interest: The authors declare no conflict of interest.

\section{References}

1. Zhao, J.; Yeates, K.; Han, Y. Analysis of high efficiency DC/DC converter processing partial input/output power. In Proceedings of the 2013 IEEE 14th Workshop on Control and Modeling for Power Electronics (COMPEL), Salt Lake City, UT, USA, 23-26 June 2013; pp. 1-8.

2. Button, R.M. An advanced photovoltaic array regulator module. In Proceedings of the IECEC 96. 31st Intersociety Energy Conversion Engineering Conference, Washington, DC, USA, 11-16 August 1996; Volume 1, pp. 519-524.

3. Agamy, M.; Harfman-Todorovic, M.; Elasser, A.; Essakiappan, S. A transformer-less partial power boost converter for PV applications using a three-level switching cell. In Proceedings of the 2013 Twenty-Eighth Annual IEEE Applied Power Electronics Conference and Exposition (APEC), Long Beach, CA, USA, 17-21 March 2013; pp. 2934-2939.

4. Badawy, M.O.; Sozer, Y. A partial power processing of battery/ultra-Capacitor hybrid energy storage system for electric vehicles. In Proceedings of the 2015 IEEE Applied Power Electronics Conference and Exposition (APEC), Charlotte, NC, USA, 15-19 March 2015; pp. 3162-3168.

5. Kasper, M.; Bortis, D.; Friedli, T.; Kolar, J.W. Classification and comparative evaluation of PV panel integrated DC-DC converter concepts. In Proceedings of the 15th International Power Electronics and Motion Control Conference (EPE/PEMC), Novi Sad, Serbia, 4-6 September 2012; pp. LS1e.4-1-LS1e.4-8.

6. Zapata, J.W.; Meynard, T.A.; Kouro, S. Partial power DC-DC converter for large-scale photovoltaic systems. In Proceedings of the 2016 IEEE 2nd Annual Southern Power Electronics Conference (SPEC), Auckland, New Zealand, 5-8 December 2016; pp. 1-6.

7. Ahmad, M.W.; Anand, S. Power decoupling in solar PV system using partial power processing converter. In Proceedings of the 2016 10th International Conference on Compatibility, Power Electronics and Power Engineering (CPE-POWERENG), Bydgoszcz, Poland, 29 June-1 July 2016; pp. 196-201.

8. Chen, L.; Wu, H.; Xu, P.; Hu, H.; Wan, C. A high step-down non-isolated bus converter with partial power conversion based on synchronous LLC resonant converter. In Proceedings of the 2015 IEEE Applied Power Electronics Conference and Exposition (APEC), Charlotte, NC, USA, 15-19 March 2015; pp. 1950-1955.

9. Zhao, J.; Han, Y. A GaN-based partial power converter with MHz reconfigurable switched-capacitor and RF SEPIC. In Proceedings of the 2016 IEEE Energy Conversion Congress and Exposition (ECCE), Milwaukee, WI, USA, 18-22 September 2016; pp. 1-7.

10. Zapata, J.W.; Renaudineau, H.; Kouro, S.; Perez, M.A.; Meynard, T.A. Partial power DC-DC converter for photovoltaic microinverters. In Proceedings of the IECON 2016 - 42nd Annual Conference of the IEEE Industrial Electronics Society, Florence, Italy, 23-26 October 2016; pp. 6740-6745.

11. Agamy, M.S.; Harfman-Todorovic, M.; Elasser, A.; Chi, S.; Steigerwald, R.L.; Sabate, J.A.; McCann, A.J.; Zhang, L.; Mueller, F.J. An Efficient Partial Power Processing DC/DC Converter for Distributed PV Architectures. IEEE Trans. Power Electron. 2014, 29, 674-686. [CrossRef]

12. Suntio, T.; Kuperman, A. Comments on an Efficient Partial Power Processing DC/DC Converter for Distributed PV Architectures. IEEE Trans. Power Electron. 2015, 30, 2372. [CrossRef] 
13. Chen, M.; Gao, F.; Yang, T. A central capacitor partial power processing DC/DC converter. In Proceedings of the 2015 IEEE Energy Conversion Congress and Exposition (ECCE), Montreal, QC, Canada, 20-24 September 2015; pp. 1995-2002.

14. Chen, M.; Gao, F.; Sha, Z. A zero-voltage-transition auxiliary network for central capacitor partial power processing DC/DC converter. In Proceedings of the 2016 IEEE 8th International Power Electronics and Motion Control Conference (IPEMC-ECCE Asia), Hefei, China, 22-26 May 2016; pp. 1170-1176.

15. Elrayyah, A.; Badawey, M.; Sozer, Y. Feeding partial power into line capacitors for low cost and efficient MPPT of photovoltaic strings. In Proceedings of the 2016 IEEE Applied Power Electronics Conference and Exposition (APEC), Long Beach, CA, USA, 20-24 March 2016; pp. 392-397.

16. Zientarski, J.R.R.; Pinheiro, J.R.; da Silva Martins, M.L.; Hey, H.L. Understanding the partial power processing concept: A case-study of buck-boost dc/dc series regulator. In Proceedings of the 2015 IEEE 13th Brazilian Power Electronics Conference and 1st Southern Power Electronics Conference (COBEP/SPEC), Fortaleza, Brazil, 29 November-2 December 2015; pp. 1-6.

17. Karimi, M.; Mahdavi, M.; Torki Harchegani, A. A New Soft Switching qZSC Converter by Using Coupled Inductor. Electr. Power Compon. Syst. 2018, 46, 270-277. [CrossRef]

18. Siwakoti, Y.P.; Peng, F.Z.; Blaabjerg, F.; Loh, P.C.; Town, G.E. Impedance-Source Networks for Electric Power Conversion Part I: A Topological Review. IEEE Trans. Power Electron. 2015, 30, 699-716. [CrossRef]

19. Peng, F.Z. Z-source inverter. IEEE Trans. Ind. Appl. 2003, 39, 504-510. [CrossRef]

20. Cao, D.; Peng, F.Z. A Family of Z-source and Quasi-Z-source DC-DC Converters. In Proceedings of the 2009 Twenty-Fourth Annual IEEE Applied Power Electronics Conference and Exposition, Washington, DC, USA, 15-19 February 2009; pp. 1097-1101.

21. Chub, A.; Vinnikov, D.; Blaabjerg, F.; Peng, F.Z. A Review of Galvanically Isolated Impedance-Source DC-DC Converters. IEEE Trans. Power Electron. 2016, 31, 2808-2828. [CrossRef]

22. Ran, Y.; Wang, W.; Liu, K.; Liu, H. A Power Decoupling Solution for Improved Y-Source Single-Phase Grid-Connected Inverter. Electr. Power Compon. Syst. 2018, 1-12. [CrossRef]

23. Ellabban, O.; Abu-Rub, H. Z-Source Inverter: Topology Improvements Review. IEEE Ind. Electron. Mag. 2016, 10, 6-24. [CrossRef]

24. Siwakoti, Y.P.; Peng, F.Z.; Blaabjerg, F.; Loh, P.C.; Town, G.E.; Yang, S. Impedance-Source Networks for Electric Power Conversion Part II: Review of Control and Modulation Techniques. IEEE Trans. Power Electron. 2015, 30, 1887-1906. [CrossRef]

25. Beer, K.; Piepenbreier, B. Properties and advantages of the quasi-Z-source inverter for DC-AC conversion for electric vehicle applications. In Proceedings of the 2010 Emobility—Electrical Power Train, Leipzig, Germany, 8-9 November 2010; pp. 1-6.

26. Nabinejad, A.; Rajaei, A.; Mardaneh, M. A Systematic Approach to Extract State Space Averaged Equations and Small Signal Model of Partial Power Converters. IEEE J. Emerg. Sel. Top. Power Electron. 2019, in press. [CrossRef]

(C) 2019 by the authors. Licensee MDPI, Basel, Switzerland. This article is an open access article distributed under the terms and conditions of the Creative Commons Attribution (CC BY) license (http://creativecommons.org/licenses/by/4.0/). 